\title{
Aortic Arch Calcification Is Associated With Death From Cardiovascular Disease, Infection, and Malnutrition in Patients on Hemodialysis: a Retrospective Cohort Study
}

\section{Toyohiro Hashiba}

Mitsui Memorial Hospital

Mototsugu Tanaka

Niigata University Medical and Dental Hospital

Tomoko Honda

Mitsui Memorial Hospital

Satoru Kishi

Mitsui Memorial Hospital

Yoshiyasu Ogura

Mitsui Memorial Hospital

Yuto Takenaka

Mitsui Memorial Hospital

Satoshi Furuse

Mitsui Memorial Hospital

Kyosuke Nishio

Shinkoiwa Clinic

Kazunobu Masaki

Shinkoiwa Clinic

\section{Tatsuya Kano}

Shinkoiwa Clinic Funabori

Naobumi Mise ( $\nabla$ misenn@mitsuihosp.or.jp )

Mitsui Memorial Hospital

\section{Research Article}

Keywords: cause of death, end-stage kidney disease, malnutrition, mortality, vascular calcification

Posted Date: June 30th, 2021

DOI: https://doi.org/10.21203/rs.3.rs-659331/v1 
License: (c) (i) This work is licensed under a Creative Commons Attribution 4.0 International License. Read Full License 


\section{Abstract}

Background: Aortic arch calcification (AAC) is a well-known risk factor of death in patients on hemodialysis (HD); however, the causes of death in those having severe AAC have not been well studied. This study aimed to clarify the association between AAC and causes of death in HD patients and investigate their long-term prognosis.

Methods: A retrospective observational study was conducted on Japanese HD patients from two clinics. AAC was classified into grade 0 to 3 using chest radiograph. The patients were followed up to 7 years, and their mortality and causes of death were recorded. The Kaplan-Meier method was used to estimate the probabilities of death from any cause and cardiovascular disease (CVD) death. The Cox proportional hazard models were employed to investigate variables relevant to all-cause mortality.

Results: Among 321 patients ( 211 male, $64 \pm 11$ years old, $10 \pm 8$ years of dialysis duration), AAC grade 0 , 1,2 , and 3 were observed in $88(27.4 \%), 145(45.2 \%), 54$ (16.8\%), and $34(10.6 \%)$, respectively. During 5.2 \pm 2.1 years, $117(36.4 \%)$ patients died. AAC was associated with all-cause mortality $(p<.001)$, and the death rates in AAC grade $0,1,2$, and 3 were $19.3 \%, 35.2 \%, 46.3 \%$, and $70.6 \%$, respectively. In multivariate analysis, grade 3 AAC, age, ischemic heart disease and C-reactive protein were independent risk factors for all-cause mortality. The major causes of death were CVD (39.3\%), infection (20.5\%), and malignant tumor (15.4\%) in the entire cohort. In AAC grade 3, death from infection (29.2\%) and malnutrition (16.7\%) increased and the combined death from these 2 reasons outweighed CVD death (33.3\%).

Conclusions: Although AAC was associated with all-cause and CVD mortality, the causes of death in patients on HD much differ among different AAC severities. Attention should be paid to CVD, infection, and malnutrition in patients on HD with severe AAC.

\section{Backgrounds}

Aortic arch calcification (AAC) in chest radiograph has been reported as a risk factor for morbidity and mortality in patients on hemodialysis (HD). Previous studies have shown that the grade of AAC was associated with death from any cause and cardiovascular diseases (CVD) in HD patients [1] [2]. A recent meta-analysis on eight cohort studies on HD patients revealed that AAC has resulted in a $44 \%$ and $130 \%$ increase in all-cause mortality and CVD death, respectively [3].

CVD is the leading cause of death among HD patients worldwide [4]. In Japan, the major causes of death in patients on maintenance dialysis were CVD (33.1\%) followed by infection (21.3\%) and malignant tumor (8.4\%), according to the annual reports from the Japanese Society for Dialysis Therapy (JSDT) [5]. Dialysis patients often show advanced aortic calcification, and vascular calcification may contribute to CVD death in HD patients. However, the detailed causes of death in HD patients with severe AAC have not been well studied so far. 
This study aimed to clarify the association between AAC and causes of death, and their long-term prognosis in patients on HD.

\section{Methods}

\section{Patients}

A retrospective observational study was conducted on Japanese HD patients from two clinics. As our previous study [6], we recruited 366 patients who were treated on maintenance HD therapy in Shinkoiwa Clinic and Shinkoiwa Clinic Funabori, Tokyo, Japan between January and March 2012. Forty-five patients were then excluded because of deficits of clinical parameters. Finally, 321 patients were enrolled in this study and were followed until the end of 2018, renal transplantation, or loss to follow-up. The main outcome of this study was the causes of death by AAC grades. All-cause mortality and CVD death rate by AAC grades were also examined.

\section{AAC grading}

AAC in chest radiograph was classified into four grades. The definition of AAC grades was described elsewhere [7]. Briefly, grade 0 indicated no visible calcification, grade 1 indicated small spots of calcification or single thin calcification of the aortic knob, grade 2 indicated one or more areas of thick calcification, and grade 3 indicated circular calcification of the aortic knob.

Data collection

All data were collected from medical records. Baseline data included age, sex, hypertension, diabetes mellitus, ischemic heart disease, stroke, hemoglobin, corrected serum calcium, serum phosphorus, serum albumin, C-reactive protein, use of $\mathrm{CaCO}_{3}$, Ca-free phosphate binders, and vitamin D3. Hypertension was defined as blood pressure greater than $140 / 90 \mathrm{mmHg}$, use of antihypertensive agents, or those having its medical history. Diabetes mellitus was defined as the use of anti-glycemic agents or those with its medical history.

Causes of death was based on the report of the death certificate and medical records. CVD included sudden cardiac death, ischemic heart disease, heart failure, peripheral arterial disease, and stroke. Deaths with no reported cause were categorized as missing [8].

Statistical analysis

Values were expressed as mean \pm standard deviation or median (interquartile range), as appropriate. A comparison of continuous variables among all AAC groups was performed using the ANOVA. Categorical data were compared using the Fisher's exact test. The Kaplan-Meier method with censoring for renal transplantations or loss to follow-up was used to estimate the probabilities of death from any cause and CVD death and was statistically tested with the log-rank test. Variables relevant to all-cause mortality were identified by the univariate Cox proportional hazard models. Multivariate Cox proportional hazard 
analyses were performed using two models: Model 1 included all significant variables in the univariate analyses, and Model 2 included statistically relevant variables using a backward stepwise method.

As this was an exploratory analysis, we considered $p$ values $<0.05$ as statistically significant. All statistical tests were performed using JMP 13.0.0 (SAS Institute Inc., Cary, North Carolina, USA).

\section{Results}

Among 321 patients (211 male, $64 \pm 11$ years old, $10 \pm 8$ years of dialysis duration), AAC grade $0,1,2$, and 3 were identified in 88 (27.4\%), 145 (45.2\%), 54 (16.8\%), and 34 (10.6\%) patients, respectively (Table 1). The patients with higher AAC grades were older and had a longer dialysis vintage and showed lower albumin levels than those with lower AAC grades. The prevalence of hypertension, diabetes mellitus, and the use of $\mathrm{CaCO}_{3}$ was relatively lower in patients with AAC grade 3 than those with AAC grade 0 to 2 .

During the mean observation period of $5.2 \pm 2.1$ years, 117 (36.4\%) patients died from any cause. Allcause mortality increased in accordance with the increase in AAC grade $(\mathrm{p}<.001)$, and the death rates in AAC grade $0,1,2$, and 3 were $19.3 \%, 35.2 \%, 46.3 \%$, and 70.6\%, respectively (Fig. 1A). CVD was also more common in patients with higher AAC grades than those with lower grades $(p=0.011)$ (Fig. 1B). Univariate analyses showed that AAC grade 1 to 3 , age, ischemic heart disease, stroke, serum albumin, hemoglobin, C-reactive protein, and use of Ca-free phosphate binders were the significant variables for all-cause mortality (Table 2). On a multivariate analysis, grade 3 AAC remains a significant risk factor for all-cause mortality, even after adjustment for all significant variables in univariate analysis (Table 3, Model 1). Further, the significant association between grade 3 AAC and all-cause mortality was also found in another Cox proportinal hazard model using a backward stepwise method (Table 3, Model 2).

The major causes of death were CVD (39.3\%), infection (20.5\%), and malignant tumor (15.4\%) in the entire cohort (Table 4). Among CVD death, sudden cardiac death (14.5\%), stroke (10.3\%), and heart failure $(9.4 \%)$ were the major causes in the entire cohort. However, in patients with AAC grade 3 , stroke was the most common reason and accounted for $16.7 \%$ of total death, which was mostly due to an increase in cerebral infarction. The proportion of CVD death for total death did not differ among AAC grades. In AAC grade 3 , death from infection (29.2\%) and malnutrition (16.7\%) increased markedly and the combined death form these 2 reasons outweighed CVD death (33.3\%).

\section{Discussion}

This study showed that AAC was associated with all-cause and CVD mortality in HD patients, as had been reported [1] [2] [3]. The major causes of death were CVD, infection, and malnutrition. The combined mortality of infection and malnutrition was higher than that of CVD in the most severe AAC group. The HD patients with more severe AAC were older than those with milder AAC, which may influence an increase in death from infection and malnutrition. These findings highlight the importance of paying 
more attention to the occurrence of fatal infection and the management of nutrition in HD patients with severe AAC.

In this study, CVD was the most common cause of death in HD patients with all AAC grades. A previous study showed that CVD mortality accounted for $37.7 \%$ of total death in patients with severe AAC, and those rates by AAC grade $0,1,2$, and 3 were $5.3 \%, 12.7 \%, 18.9 \%$, and $24.4 \%$, respectively [2]. However, in this study, there was no clear difference in CVD mortality among AAC grades. The low prevalence of diabetes mellitus, a well-known poor prognostic factor, may have influenced no increase in CVD mortality in HD patients with severe AAC [9]. In addition, ischemic stroke mortality tended to occur more frequently in patients with severe AAC. This result was compatible with a previous report that the incidence of cerebral infarction was associated with calcification of the thoracic aorta [10]. Moreover, a recent report showed that CVD risk profiles in both sexes that were differentially associated with calcification at multiple vascular sites [11]. Although gender association was not clear in this study, this report supports the importance of assessing AAC, which is a potential risk factor for CVD.

The HD patients with severe AAC in this study were older than patients on maintenance dialysis in Japan and were more likely to die from infection and malnutrition [5]. Elderly HD patients may have malnutrition, inflammation, and atherosclerosis (MIA) syndrome that is associated with an elevated mortality in dialysis patients[12]. Malnutrition and inflammation were significantly associated with AAC progression, which was evaluated by using lateral lumbar radiography [13]. Moreover, Okamoto et al. reported that poor nutritional status was an independent risk factor for the progression of aortic calcification in HD patients [14].

Further, it has been reported that elderly HD patients often died of infectious diseases, including pneumonia and sepsis [15]. In this study, the mean serum albumin level tended to be lower in more severe AAC groups. Therefore, the prevalence of MIA syndrome may be higher in patients with higher AAC grades, and those patients may have contributed to the increase in mortality due to infection and malnutrition. On the other hand, the association between AAC grade 3 and all-cause mortality remained significant after adjustment of covariates, suggesting the existence of other factors that we did not adjust in a multivariate analysis.

There are various methods for the evaluation of vascular calcification related to mortality. It has been reported that AAC evaluated by coronary Computed Tomography (CT) and 3D-CT can also predict CV events [16] [17]. In addition, there were several reports that the calcification score on abdominal radiograph can predict CV events [18] [19]. It is necessary to consider a more appropriate evaluation method, including not only predictive hit ratio but also cost and invasiveness. Although Bohn et al. evaluated that AAC did not provide additional information on the prediction of mortality, we found the causes of death in patients on HD much differ among different AAC severities [20]. Thus, we emphasize that the assessment of AAC is useful in predicting all causes of death and should pay attention to especially infection and nutrition. 
The study has several strengths. The design of the study was simple and the AAC assessment was easy to perform on a routine chest radiograph. The long observation period of this study allowed us to detect the clear difference in all-cause mortality and CVD mortality despite the survival rate of HD patients in Japan is much longer than that in Western countries [21]. A recent randomized controlled trial showed an intensive control of hyperphosphatemia resulted in reduction of AAC [22]. The strong association between AAC and all-cause mortality in this study supports the necessity of an appropriate management of hyperphosphatemia in patients on HD. On the other hand, there are several limitations in this study. Firstly, the AAC grading based on a plain chest radiograph may be biased by the investigators. However, this method has several advantages such as simplicity and cost, and thus is available in clinical practice. Secondly, we could not exclude the effect of changes in AAC and laboratory data during the study period on all-cause mortality and causes of death, since our analyses were based on baseline data. Thirdly, this study was conducted on patients from two HD clinics in Japan that may limit the generalizability of the study results. Although the baseline characteristics of the patients in this study appeared to be close to the nation-wide Japanese dialysis cohort, our patients were slightly younger, had a longer dialysis vintage, and used more phosphate-binders than those of the JSDT population [5].

\section{Conclusions}

This study demonstrated that in HD patients with severe AAC, deaths from infection and malnutrition were often observed, as well as CVD deaths. Dialysis patients with advanced vascular calcification are often elderly and it is important to pay more attention to the development of fatal infection and to prevent malnutrition.

\section{Abbreviations}

AAC『aortic arch calcification, CVD囚cardiovascular disease, CRP囚C-reactive protein, CT囚Computed

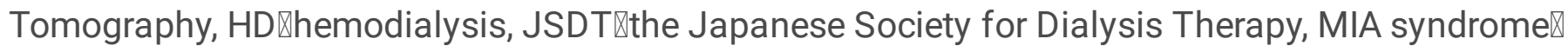
malnutrition, inflammation, and atherosclerosis syndrome.

\section{Declarations}

\section{Ethics approval and consent to participate}

The study was conducted in compliance with the Declaration of Helsinki and approved by the ethics committee in the Mitsui Memorial Hospital, Tokyo, Japan (Approved number: C75). The institutional review board waived the requirement for informed consent from the patients according to the ethical guidelines for medical and health research involving human subjects in Japan.

\section{Consent for publication}

Not applicable. 
Availability of data and materials

The datasets used and/or analyzed during the current study are available from the corresponding author on reasonable request.

\section{Competing Interests}

All the authors declared no competing interests.

\section{Funding}

None.

\section{Authors' Contributions}

T. Hashiba and NM designed this study. T. Hashiba, T. Honda, SK, YO, YT, SF, KN, KM, TK and NM collected data. T. Hashiba performed analysis. T. Hashiba, MT and NM drafted the manuscript.

\section{Acknowledgements}

We appreciate the medical staff in Shinkoiwa Clinic and Shinkoiwa Clinic Funabori (Tokyo, Japan) for data collection.

\section{References}

1. Komatsu M, Okazaki M, Tsuchiya K, Kawaguchi H, Nitta K: Aortic arch calcification predicts cardiovascular and all-cause mortality in maintenance hemodialysis patients. Kidney Blood Press Res 2014, 39(6):658-667.

2. Lee CT, Huang CC, Hsu CY, Chiou TT, Ng HY, Wu CH, Kuo WH, Lee YT: Calcification of the aortic arch predicts cardiovascular and all-cause mortality in chronic hemodialysis patients. Cardiorenal Med 2014, 4(1):34-42.

3. Zhang A, Wang S, Li H, Yang J, Wu H: Aortic arch calcification and risk of cardiovascular or all-cause and mortality in dialysis patients: A meta-analysis. Sci Rep 2016, 6:35375.

4. Cozzolino M, Mangano M, Stucchi A, Ciceri P, Conte F, Galassi A: Cardiovascular disease in dialysis patients. Nephrol Dial Transplant 2018, 33(suppl_3):iii28-iii34.

5. K.Nitta IM, N.Hanafusa, S.Gotou, M.Abe, H.Nakamoto et al. : Annual Dialysis Data Report, JSDT Renal Data Registry. Journal of Japanese Society for Dialysis Therapy 2018 52(12):679-754.

6. Honda T, Kishi S, Furukawa E, Ambe H, Kurata Y, Ichikawa M, Aoe M, Ohara K, Furuse S, Saito K et al: Eicosapentaenoic Acid and Prevalence of Cardiovascular Disease in Hemodialysis Patients. Ther Apher Dial 2018, 22(5):514-518.

7. Symeonidis GP, N;Giannakis, l;Mavridis, G;et al: Gravity of aortic arch calcification as evaluated in adult Greek patients. International Angiology 2002, 21(3):233. 
8. Thompson S, James M, Wiebe N, Hemmelgarn B, Manns B, Klarenbach S, Tonelli M, Alberta Kidney Disease N: Cause of Death in Patients with Reduced Kidney Function. J Am Soc Nephro/2015, 26(10):2504-2511.

9. Taniwaki H, Ishimura E, Tabata T, Tsujimoto Y, Shioi A, Shoji T, Inaba M, Inoue T, Nishizawa Y: Aortic calcification in haemodialysis patients with diabetes mellitus. Nephrol Dial Transplant 2005, 20(11):2472-2478.

10. Hermann DM, Lehmann N, Gronewold J, Bauer M, Mahabadi AA, Weimar C, Berger K, Moebus S, Jockel $\mathrm{KH}$, Erbel $\mathrm{R}$ et al: Thoracic aortic calcification is associated with incident stroke in the general population in addition to established risk factors. Eur Heart J Cardiovasc Imaging 2015, 16(6):684690.

11. van der Toorn JE, Rueda-Ochoa OL, van der Schaft N, Vernooij MW, Ikram MA, Bos D, Kavousi M: Arterial calcification at multiple sites: sex-specific cardiovascular risk profiles and mortality risk-the Rotterdam Study. BMC Med 2020, 18(1):263.

12. Hirokazu Honda TA: MIA syndrome in dialysis patients. The Japanese Journal of Clinical Dialysis 2013, 29(8):13-18.

13. Choi SR, Lee YK, Cho AJ, Park HC, Han CH, Choi MJ, Koo JR, Yoon JW, Noh JW: Malnutrition, inflammation, progression of vascular calcification and survival: Inter-relationships in hemodialysis patients. PLoS One 2019, 14(5):e0216415.

14. Okamoto T, Hatakeyama S, Kodama H, Horiguchi H, Kubota Y, Kido K, Momota M, Hosogoe S, Tanaka $Y$, Takashima $T$ et al: The relationship between poor nutritional status and progression of aortic calcification in patients on maintenance hemodialysis. BMC Nephrol 2018, 19(1):71.

15. T.Harada SF: An overview of high mortality rate of infectious diseases in hemodialysis patients. Journal of Japanese Society for Dialysis Therapy 2013, 28(3):374-379.

16. Hanada S, Ando R, Naito S, Kobayashi N, Wakabayashi M, Hata T, Sasaki S: Assessment and significance of abdominal aortic calcification in chronic kidney disease. Nephrol Dial Transplant 2010, 25(6):1888-1895.

17. Kamiura N, Yamamoto K, Okada S, Sakai M, Fujimori A: Calcification of the thoracic aorta determined by threedimensional computed tomography predicts cardiovascular complications in patients undergoing hemodialysis. Int Urol Nephrol 2014, 46(5):993-998.

18. Okuno S, Ishimura E, Kitatani K, Fujino Y, Kohno K, Maeno Y, Maekawa K, Yamakawa T, Imanishi Y, Inaba $\mathrm{M}$ et al: Presence of abdominal aortic calcification is significantly associated with all-cause and cardiovascular mortality in maintenance hemodialysis patients. Am J Kidney Dis 2007, 49(3):417-425.

19. R.Tomaru KI: Relationship of abdominal aortic calcification documented by abdominal plain X-ray at the onset of congestive heart failure and overall mortality in chronic hemodialysis patients. . Journal of Japanese Society for Dialysis Therapy 2015, 48(5):295-301.

20. E.Bohn NT, B.Gali, B.Henderson, MM,Sood, P.Komenda et al.: Predicting risk of mortality in dialysis patients:a retrospective cohort study evaluating the prognostic value of a simple chest $\mathrm{X}$-ray. $B M C$ 
Nephrology 2013, 14.

21. Stirnadel-Farrant HA, Karaboyas A, Cizman B, Bieber BA, Kler L, Jones D, Cobitz AR, Robinson BM: Cardiovascular Event Rates Among Hemodialysis Patients Across Geographical Regions-A Snapshot From The Dialysis Outcomes and Practice Patterns Study (DOPPS). Kidney Int Rep 2019, 4(6):864872.

22. Isaka Y, Hamano T, Fujii H, Tsujimoto Y, Koiwa F, Sakaguchi Y, Tanaka R, Tomiyama N, Tatsugami F, Teramukai S: Optimal Phosphate Control Related to Coronary Artery Calcification in Dialysis Patients. J Am Soc Nephrol 2021, 32(3):723-735.

\section{Tables}


Table 1

Baseline characteristics of the participants by aortic arch calcification grade.

\begin{tabular}{|c|c|c|c|c|c|c|}
\hline Variable & $\begin{array}{l}\text { All } \\
N=321\end{array}$ & $\begin{array}{l}\text { Grade } 0 \\
N=88\end{array}$ & $\begin{array}{l}\text { Grade } 1 \\
N=145\end{array}$ & $\begin{array}{l}\text { Grade } 2 \\
\mathrm{~N}=54\end{array}$ & $\begin{array}{l}\text { Grade } 3 \\
N=34\end{array}$ & $\begin{array}{l}P \\
\text { value }\end{array}$ \\
\hline Age (year) & $64 \pm 11$ & $57 \pm 11$ & $65 \pm 11$ & $66 \pm 8$ & $73 \pm 7$ & $<.001$ \\
\hline Male, n (\%) & $\begin{array}{l}211 \\
(65.7)\end{array}$ & $\begin{array}{l}59 \\
(67.1)\end{array}$ & $\begin{array}{l}100 \\
(69.0)\end{array}$ & $29(53.7)$ & $23(67.7)$ & 0.245 \\
\hline Dialysis vintage (year) & $9.7 \pm 8.2$ & $8.2 \pm 7.4$ & $9.3 \pm 8.0$ & $\begin{array}{l}12.8 \pm \\
9.1\end{array}$ & $\begin{array}{l}10.8 \pm \\
8.5\end{array}$ & 0.010 \\
\hline Diabetes, n (\%) & $\begin{array}{l}131 \\
(40.8)\end{array}$ & $\begin{array}{l}45 \\
(51.1)\end{array}$ & $\begin{array}{l}56 \\
(38.6)\end{array}$ & $24(44.4)$ & $6(17.7)$ & 0.006 \\
\hline Hypertension, n (\%) & $\begin{array}{l}177 \\
(55.1)\end{array}$ & $\begin{array}{l}41 \\
(46.6)\end{array}$ & $\begin{array}{l}91 \\
(62.8)\end{array}$ & $31(57.4)$ & $14(41.2)$ & 0.032 \\
\hline Ischemic heart disease, $\mathrm{n}(\%)$ & $\begin{array}{l}65 \\
(20.3)\end{array}$ & $\begin{array}{l}14 \\
(15.9)\end{array}$ & $\begin{array}{l}31 \\
(21.4)\end{array}$ & $16(29.6)$ & $4(11.8)$ & 0.148 \\
\hline Stroke, n (\%) & $\begin{array}{l}84 \\
(26.2)\end{array}$ & $\begin{array}{l}17 \\
(19.3)\end{array}$ & $\begin{array}{l}35 \\
(24.1)\end{array}$ & $20(37.0)$ & $12(35.3)$ & 0.064 \\
\hline Serum albumin (g/dL) & $3.7 \pm 0.3$ & $3.7 \pm 0.3$ & $3.7 \pm 0.3$ & $3.6 \pm 0.3$ & $3.4 \pm 0.3$ & $<.001$ \\
\hline Hemoglobin (g/dL) & $\begin{array}{l}10.0 \pm \\
0.9\end{array}$ & $\begin{array}{l}10.2 \pm \\
0.9\end{array}$ & $9.9 \pm 0.8$ & $\begin{array}{l}10.0 \pm \\
1.0\end{array}$ & $9.9 \pm 0.9$ & 0.108 \\
\hline C-reactive protein (mg/dL) & $\begin{array}{l}0.1(0.0- \\
0.3)\end{array}$ & $\begin{array}{l}0.1(0.0- \\
0.3)\end{array}$ & $\begin{array}{l}0.1(0.0- \\
0.4)\end{array}$ & $\begin{array}{l}0.1(0.0- \\
0.2)\end{array}$ & $\begin{array}{l}0.2(0.0- \\
0.4)\end{array}$ & 0.525 \\
\hline $\begin{array}{l}\text { Corrected serum calcium } \\
\text { (mg/dL) }\end{array}$ & $9.2 \pm 0.5$ & $9.1 \pm 0.6$ & $9.2 \pm 0.5$ & $9.2 \pm 0.5$ & $9.4 \pm 0.5$ & 0.120 \\
\hline Serum phosphorus (mg/dL) & $5.9 \pm 1.3$ & $6.0 \pm 1.5$ & $5.9 \pm 1.3$ & $5.8 \pm 1.2$ & $5.8 \pm 1.0$ & 0.712 \\
\hline Use of $\mathrm{CaCO}_{3}, \mathrm{n}(\%)$ & $\begin{array}{l}209 \\
(65.3)\end{array}$ & $\begin{array}{l}61 \\
(70.1)\end{array}$ & $\begin{array}{l}99 \\
(68.3)\end{array}$ & $34(63.0)$ & $15(44.1)$ & 0.045 \\
\hline $\begin{array}{l}\text { Use of Ca-free phosphate } \\
\text { binders, } \mathrm{n}(\%)\end{array}$ & $\begin{array}{l}179 \\
(55.9)\end{array}$ & $\begin{array}{l}53 \\
(60.9)\end{array}$ & $80(55 \%)$ & $28(51.9)$ & $18(52.9)$ & 0.705 \\
\hline Use of vitamin D3, n (\%) & $\begin{array}{l}117 \\
(36.6)\end{array}$ & $\begin{array}{l}30 \\
(34.5)\end{array}$ & $\begin{array}{l}57 \\
(39.3)\end{array}$ & 18 (33.3) & $12(35.3)$ & 0.840 \\
\hline
\end{tabular}

Values are expressed as mean \pm standard deviation or median (interquartile range). Values in boldface type are significant $(p<.05)$. Abbreviations: AAC, aortic arch calcification. 
Table 2

Univariate Cox proportional hazard analysis for all-cause mortality.

\begin{tabular}{|llll|}
\hline Variable & HR & $95 \% \mathrm{Cl}$ & P value \\
\hline${\text { AAC grade }{ }^{*}}^{*}$ & 1.98 & $1.14-3.42$ & 0.015 \\
\hline${\text { AAC grade }{ }^{*}}^{*}$ & 2.78 & $1.50-5.15$ & 0.001 \\
\hline AAC grade ${ }^{*}$ & 5.72 & $3.06-10.7$ & $<.001$ \\
\hline Age (10 years) & 1.85 & $1.55-2.22$ & $<.001$ \\
\hline Male & 0.74 & $0.51-1.06$ & 0.101 \\
\hline Dialysis vintage (year) & 1.02 & $0.99-1.04$ & 0.168 \\
\hline Diabetes & 1.28 & $0.88-1.84$ & 0.222 \\
\hline Hypertension & 1.13 & $0.79-1.64$ & 0.497 \\
\hline Ischemic heart disease & 1.79 & $1.19-2.69$ & 0.005 \\
\hline Stroke & 1.81 & $1.24-2.66$ & 0.002 \\
\hline Corrected serum calcium (mg/dL) & 0.99 & $0.70-1.41$ & 0.968 \\
\hline Serum phosphorus (mg/dL) & 0.88 & $0.76-1.01$ & 0.078 \\
\hline Serum albumin (g/dL) & 0.18 & $0.10-0.34$ & $<.001$ \\
\hline Hemoglobin (g/dL) & 0.77 & $0.62-0.94$ & 0.011 \\
\hline C-reactive protein (mg/dL) & 1.44 & $1.22-1.66$ & $<.001$ \\
\hline Use of CaCO 3 & 0.70 & $0.48-1.00$ & 0.053 \\
\hline Use of Ca-free phosphate binders & 0.63 & $0.44-0.91$ & 0.013 \\
\hline Use of vitamin D3 & 0.99 & $0.68-1.45$ & 0.972 \\
\hline
\end{tabular}

*AAC grade 0 was used as reference. Values in boldface type are significant $(p<.05)$.

Abbreviations: AAC, aortic arch calcification $\otimes \mathrm{HR}$, hazard ratio; $\mathrm{Cl}$, confidence interval. 
Table 3

Multivariate analysis for all-cause mortality.

\begin{tabular}{|c|c|c|c|c|c|c|}
\hline \multirow[t]{2}{*}{ Variable } & \multicolumn{3}{|c|}{ Model 1} & \multicolumn{3}{|c|}{ Model 2} \\
\hline & HR & $95 \% \mathrm{Cl}$ & $P$ value & HR & $95 \% \mathrm{Cl}$ & $P$ value \\
\hline AAC grade $1^{*}$ & 1.26 & $0.72-2.21$ & 0.411 & - & - & - \\
\hline AAC grade $2^{*}$ & 1.78 & $0.95-3.32$ & 0.070 & - & - & - \\
\hline AAC grade $3^{*}$ & 2.63 & $1.35-5.14$ & 0.005 & 2.09 & $1.29-3.37$ & 0.003 \\
\hline Age (10 years) & 1.61 & $1.29-2.03$ & $<.001$ & 1.71 & $1.41-2.09$ & $<.001$ \\
\hline Ischemic heart disease & 1.57 & $1.03-2.40$ & 0.038 & 1.54 & $1.02-2.33$ & 0.042 \\
\hline Stroke & 1.45 & $0.98-2.15$ & 0.064 & 1.47 & $0.99-2.16$ & 0.053 \\
\hline Serum albumin $(\mathrm{g} / \mathrm{dL})$ & 0.57 & $0.27-1.19$ & 0.139 & - & - & - \\
\hline Hemoglobin (g/dL) & 0.91 & $0.73-1.14$ & 0.408 & - & - & - \\
\hline C-reactive protein $(\mathrm{mg} / \mathrm{dL})$ & 1.34 & $1.12-1.56$ & $<.001$ & 1.41 & $1.19-1.63$ & $<.001$ \\
\hline Use of Ca-free phosphate binders & 1.12 & $0.75-1.69$ & 0.573 & - & - & - \\
\hline
\end{tabular}

${ }^{*} A A C$ grade 0 was used as reference. Values in boldface type are significant $(p<.05)$.

Multivariate Cox proportional hazard analyses were performed using two models: Model 1 included all significant variables in the univariate analyses, and Model 2 included relevant variables using backward stepwise method.

Abbreviations: AAC, aortic arch calcification; $\mathrm{HR}$, hazard ratio; $\mathrm{Cl}$, confidence interval. 
Table 4

The causes of death by aortic arch calcification grade.

\begin{tabular}{|llllll|}
\hline Cause of Death & All & Grade $\mathbf{0}$ & Grade 1 & Grade 2 & Grade 3 \\
$\mathbf{N = 3 2 1}$ & $\mathbf{N = 8 8}$ & $\mathbf{N = 1 4 5}$ & $\mathbf{N = 5 4}$ & $\mathbf{N = 3 4}$ \\
\hline Death from any cause & $117(36.4)$ & $17(19.3)$ & $51(35.2)$ & $25(46.3)$ & $24(70.6)$ \\
\hline CVD death & $46(39.3)$ & $6(35.3)$ & $23(45.1)$ & $9(36.0)$ & $8(33.3)$ \\
\hline Sudden cardiac death & $17(14.5)$ & $4(23.5)$ & $6(11.8)$ & $4(16.0)$ & $3(12.5)$ \\
\hline Heart failure & $11(9.4)$ & $2(11.8)$ & $7(15.7)$ & $2(8.0)$ & $0(0)$ \\
\hline Ischemic heart disease & $2(1.7)$ & $0(0)$ & $1(2.0)$ & $0(0)$ & $1(4.2)$ \\
\hline Acute aortic dissection & $1(0.3)$ & $0(0)$ & $1(2.0)$ & $0(0)$ & $0(0)$ \\
\hline Peripheral arterial disease & $3(2.6)$ & $0(0)$ & $2(3.9)$ & $1(4.0)$ & $0(0)$ \\
\hline Stroke & $12(10.3)$ & $0(0)$ & $6(11.8)$ & $2(8.0)$ & $4(16.7)$ \\
\hline Cerebral hemorrhage & $7(6.0)$ & $0(0)$ & $4(7.8)$ & $2(8.0)$ & $1(4.2)$ \\
\hline Cerebral infarction & $5(4.3)$ & $0(0)$ & $2(3.9)$ & $0(0)$ & $3(12.5)$ \\
\hline Non-CVD death & $71(60.7)$ & $11(64.7)$ & $28(54.9)$ & $16(64.0)$ & $16(66.7)$ \\
\hline Infection & $24(20.5)$ & $3(17.6)$ & $9(17.6)$ & $5(20.0)$ & $7(29.2)$ \\
\hline Malignant tumor & $18(15.4)$ & $3(17.6)$ & $8(15.7)$ & $6(24.0)$ & $1(4.2)$ \\
\hline Malnutrition & $8(6.8)$ & $2(11.8)$ & $1(2.0)$ & $1(4.0)$ & $4(16.7)$ \\
\hline Others & $11(9.4)$ & $1(5.9)$ & $6(11.8)$ & $3(12.0)$ & $1(4.2)$ \\
\hline Missing & $10(8.5)$ & $2(11.8)$ & $4(7.8)$ & $1(18.5)$ & $3(12.5)$ \\
\hline
\end{tabular}

Data are expressed as $n(\%)$. Others $\llbracket$ gastrointestinal bleeding, $n=2$; intestinal obstruction, $n=1$; hernia rupture, $n=1$; liver cirrhosis, $n=1$; acute pancreatitis, $n=1$; interstitial pneumonia, $n=1$; acute respiratory failure, $n=1$; pleuritis, $n=1$; hypoxic encephalopathy, $n=1$; trauma, $n=1$. Abbreviations: AAC, aortic arch calcification.

\section{Figures}


(A) Death from any cause

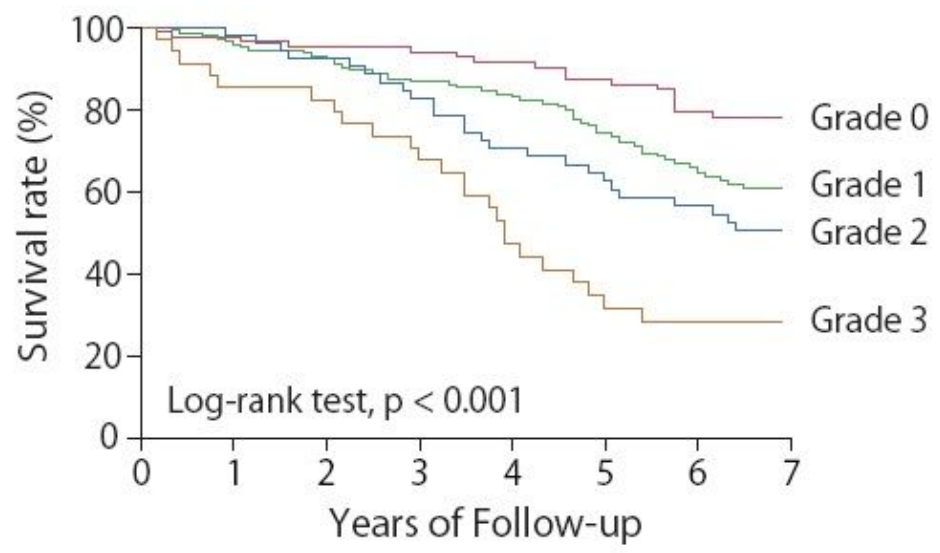

No. at Risk

$\begin{array}{ccccccccc}\text { Grade 0 } & 88 & 85 & 77 & 74 & 70 & 68 & 63 & 57 \\ \text { Grade 1 } & 145 & 140 & 134 & 121 & 109 & 92 & 79 & 71 \\ \text { Grade 2 } & 54 & 53 & 50 & 42 & 36 & 32 & 29 & 24 \\ \text { Grade 3 } & 34 & 30 & 29 & 24 & 16 & 11 & 10 & 8\end{array}$

(B) Cardiovascular death

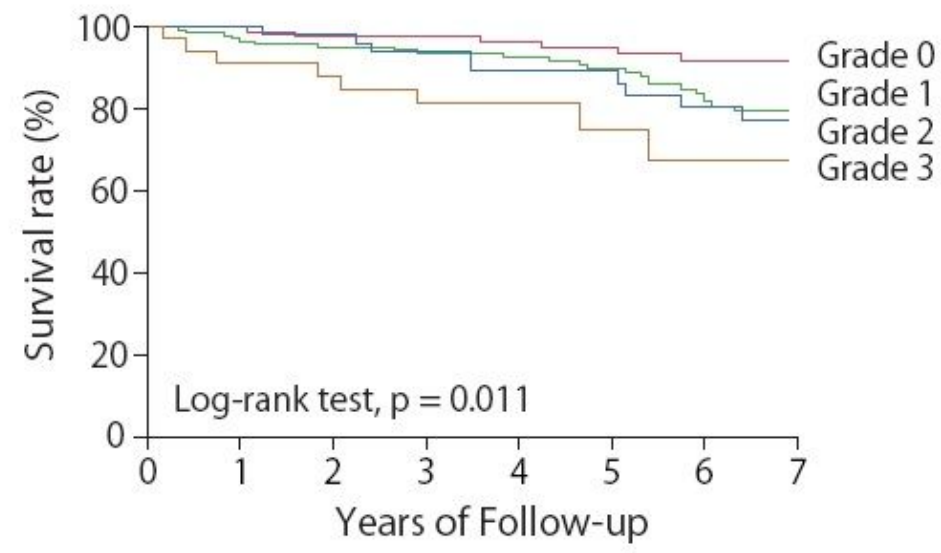

$\begin{array}{lrrrrrrrr}\text { No. at Risk } & & & & & & & & \\ \text { Grade 0 } & 88 & 85 & 77 & 74 & 70 & 68 & 63 & 57 \\ \text { Grade 1 } & 145 & 140 & 134 & 121 & 109 & 92 & 79 & 71 \\ \text { Grade 2 } & 54 & 53 & 50 & 42 & 36 & 32 & 29 & 24 \\ \text { Grade 3 } & 34 & 30 & 29 & 24 & 16 & 11 & 10 & 8\end{array}$

\section{Figure 1}

Kaplan-Meier analysis for all-cause mortality and cardiovascular death. Shown are the Kaplan-Meier analysis for (A) death from any cause and (B) CVD death by AAC grades among patients on HD. All-cause mortality and CVD death rates were significantly higher in patients with higher AAC grades. Abbreviations: AAC, aortic arch calcification; CVD, cardiovascular disease; HD, hemodialysis. 